\title{
Effects of aversive stimuli beyond defensive neural circuits: Reduced excitability in an identified neuron critical for feeding in Aplysia
}

\author{
Maria E. Shields-Johnson, ${ }^{1}$ John S. Hernandez, ${ }^{1}$ Cody Torno, ${ }^{1}$ Katherine M. Adams, \\ Marcy L. Wainwright, and Riccardo Mozzachiodi \\ Department of Life Sciences, Texas A\&M University-Corpus Christi, Corpus Christi, Texas 78412, USA
}

\begin{abstract}
In Aplysia, repeated trials of aversive stimuli produce long-term sensitization (LTS) of defensive reflexes and suppression of feeding. Whereas the cellular underpinnings of LTS have been characterized, the mechanisms of feeding suppression remained unknown. Here, we report that LTS training induced a long-term decrease in the excitability of B51 (a decisionmaking neuron in the feeding circuit) that recovered at a time point in which LTS is no longer observed $(72 \mathrm{~h}$ post-treatment). These findings indicate B51 as a locus of plasticity underlying feeding suppression. Finally, treatment with serotonin to induce LTS failed to alter feeding and B51 excitability, suggesting that serotonin does not mediate the effects of LTS training on the feeding circuit.
\end{abstract}

[Supplemental material is available for this article.]

Following exposure to aversive stimuli, an organism adaptively changes the expression of both defensive and nondefensive behaviors (Kavaliers and Choleris 2001; LeDoux 2012). Therefore, characterizing changes in both defensive and nondefensive neural circuits is paramount to fully understanding how the adaptive response is generated. The mechanisms by which aversive stimuli affect the activity of defensive neural circuits have been extensively studied in vertebrates and invertebrates (e.g., Carew and Sahley 1986; Kandel 2001; Papes et al. 2010; LeDoux 2012). However, the effects of aversive experience on nondefensive neural circuits remain largely unexplored.

In the marine mollusk Aplysia, exposure to noxious electrical stimuli, which mimic the attack of a predator (Watkins et al. 2010), induces an elementary form of nonassociative learning, known as sensitization. Sensitization manifests as enhancement of defensive responses, such as escape locomotion and withdrawal reflexes (Stopfer and Carew 1988; Kandel 2001), and is mediated by serotonin (5-HT) (e.g., Brunelli et al. 1976; Glanzman et al. 1989; Levenson et al. 2000). In Aplysia, sensitizing stimuli also induce a concomitant suppression of feeding (Acheampong et al. 2012). In particular, a 1-d training protocol, producing long-term sensitization (LTS) of the tail-elicited siphon withdrawal reflex (TSWR), suppresses feeding for at least $24 \mathrm{~h}$ (Acheampong et al. 2012). Despite the extensive knowledge of the cellular underpinnings of LTS (Kandel 2001; Fioravante et al. 2008), the neurophysiological mechanisms by which sensitizing stimuli suppress feeding remain unknown. Therefore, the goal of this study was to explore the effects of LTS training on the feeding neural circuit.

As a first step in the cellular analysis of the suppression of feeding, we focused on neuron B51 because it plays a central role in the feeding neural circuit by exhibiting decision-making

\footnotetext{
'These authors contributed equally to this work.

${ }^{2}$ Corresponding author

E-mail riccardo.mozzachiodi@tamucc.edu

Article is online at http://www.learnmem.org/cgi/doi/10.1101//m.028084.112.
}

features at the cellular level (e.g., Nargeot and Simmers 2011). B51 generates an all-or-nothing intrinsic burst of action potentials (i.e., plateau potential), which selectively occurs during ingestive buccal motor programs (BMPs) (Nargeot et al. 1999a,b; Brembs et al. 2002), the neurophysiological correlates of biting. B51 appears to influence the nature of the motor output: suprathreshold activation of B51 promotes the expression of ingestive BMPs, whereas hyperpolarization of B51 prevents their occurrence (Nargeot et al. 1999a,b). Notably, an increase in B51 excitability has been associated with the increased number of ingestive BMPs in vitro and bites in vivo produced by operant reward learning (Nargeot et al. 1999a,b; Brembs et al. 2002; Mozzachiodi et al. 2008). Therefore, B51 represents a putative site of plasticity underlying the suppression of feeding induced by LTS training. In the second part of this study, we examined whether a treatment with 5-HT, which is known to induce LTS, modulates feeding in a manner analogous to LTS training.

In all experiments, the TSWR and feeding were measured prior to (pre-test) and after (post-test) the delivery of a treatment (LTS training or 5-HT application; see Supplemental Material for details) to assess treatment-induced behavioral modifications. The duration of the siphon withdrawal was used as a measure of TSWR strength (Cleary et al. 1998). Feeding was assessed by counting the number of bites (i.e., rhythmic movements of the radula) (Kupfermann 1974; Susswein et al. 1976) generated during a 5-min test. Biting tests were conducted $30 \mathrm{~min}$ after the conclusion of the TSWR pre-test and post-tests, respectively (Acheampong et al. 2012; see Supplemental Material for details). Once post-tests were completed, the buccal ganglia were removed, and B51 membrane and synaptic properties were measured using a standard two-electrode current-clamp technique (see Supplemental Material for details about the electrophysiological measurements).

In the first experiment, we examined the effects of LTS training on the properties of neuron B51. Training consisted of four trains of electric shocks repeated at 30-min intervals (see 
Supplemental Material for details). TSWR and feeding were assessed before and $24 \mathrm{~h}$ after treatment (training/no training). Training produced concurrent LTS (change in TSWR duration, trained: $2.47 \pm 0.61, n=23$; untrained: $1.35 \pm 0.24, n=14 ; P<$ $0.05 ; U=97$ ) (Fig. 1A1) and suppression of feeding (difference in bites, trained: $-8.38 \pm 2.02$ bites, $n=29$; untrained: $-0.63 \pm$ 1.22 bites, $n=30 ; P<0.05 ; U=253$ ) (Fig. 1A2). Immediately after the 24-h post-tests, the buccal ganglia were removed, and B51 properties were measured. The threshold to elicit a plateau potential in B51 (i.e., burst threshold) was significantly greater in the trained group $(18.27 \pm 2.76 \mathrm{nA}, n=11)$ than in the untrained group (9.97 $\pm 0.88 \mathrm{nA}, n=15 ; P<0.05 ; U=36$ ) (Fig. 1B1,B2).
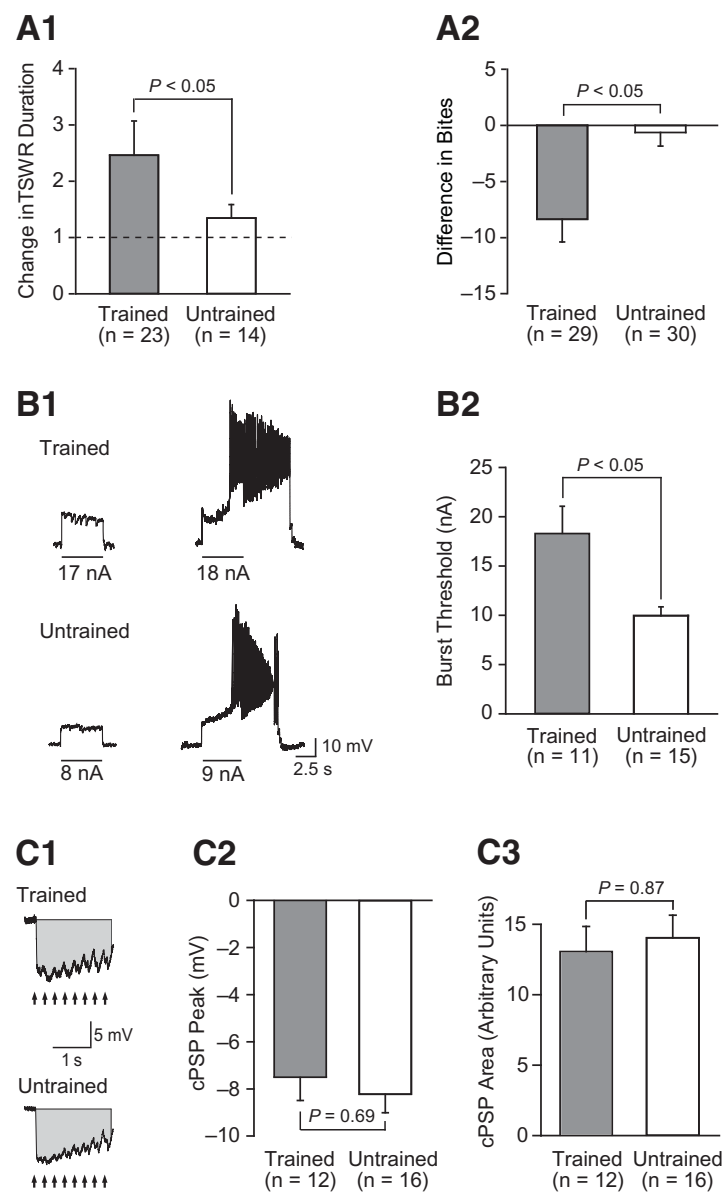

Figure 1. LTS training reduced B51 excitability through an increase in burst threshold $24 \mathrm{~h}$ after training. Training produced concomitant LTS (A1) and suppression of feeding (A2) $24 \mathrm{~h}$ after treatment. In this and the following figures, changes in TSWR duration (i.e., [post-test TSWR duration]/[pre-test TSWR duration]) and differences in bites (i.e., bites during post-test minus bites during pre-test) were used to analyze behavioral modifications due to treatment. (B) LTS training increased B51 burst threshold. (B1) Sample traces of B51 burst threshold from trained and untrained animals. (B2) Summary data illustrate that LTS training significantly increased B51 burst threshold. (C) LTS training did not affect the synaptic input to B51. (C1) Sample traces of n.2,3-evoked CPSP in B51 from trained and untrained animals. The shaded area underneath each trace indicates the area of the CPSP over $2 \mathrm{sec}$ of n.2,3 stimulation. Individual stimuli are indicated with arrows below the recordings. Summary data illustrate that the peak amplitude (C2) and the area (C3) of the n.2,3-evoked CPSP did not differ between trained and untrained animals. In these and the following figures, values are expressed as mean \pm SEM and statistical significance is set at $P<0.05$. The MannWhitney $U$-test was used to compare behavioral and electrophysiological measurements between treated and control groups.
The increase in burst threshold was not accompanied by modifications of resting membrane potential (trained: $-59.35 \pm$ $1.26 \mathrm{mV}, n=17$; untrained: $-62.42 \pm 1.17 \mathrm{mV}, n=19 ; P=0.35$; $U=131.5$ ) or input resistance (trained: $2.19 \pm 0.14 \mathrm{M} \Omega, n=15$; untrained: $2.15 \pm 0.12 \mathrm{M} \Omega, n=16 ; P=0.77 ; U=112$ ).

We next investigated whether changes in the synaptic input to B51 were also observed following LTS training. Electrical stimulation of buccal nerve n.2,3 activates the buccal feeding circuit (Nargeot et al. 1999a,b) and evokes a primarily inhibitory complex synaptic potential in B51 (CPSP) (Fig. 1C1). The peak amplitude and the area of the cPSP produced by 2 sec of n.2,3 stimulation were measured in the same animals used for the analysis of B51 membrane properties (see Supplemental Material for details). Neither the peak amplitude (trained: $-7.50 \pm 0.99 \mathrm{mV}$, $n=12$; untrained: $-8.24 \pm 0.77 \mathrm{mV}, n=16 ; P=0.69 ; U=87$ ) (Fig. 1C1,C2) nor the area (trained: $13.06 \pm 1.78$ arbitrary units, $n=12$; untrained: $14.04 \pm 1.60$ arbitrary units, $n=16 ; P=0.87$; $U=92$ ) (Fig. 1C1,C3) of the cPSP differed between trained and untrained animals. The lack of changes in resting membrane potential and synaptic input indicates that the increase in B51 burst threshold is representative of a reduced excitability intrinsic to the neuron and not due to modifications of synaptic inputs from presynaptic sources, thus implicating B51 as a site of plasticity underlying the suppression of feeding.

If the decrease in B51 excitability, observed $24 \mathrm{~h}$ after treatment, contributes to the suppression of feeding, it should not be measured once feeding has recovered from the suppressive effect of LTS training. The training protocol used in this study is known to induce LTS that persists for at least $48 \mathrm{~h}$, but not $72 \mathrm{~h}$, after treatment (Khabour et al. 2004). Therefore, in the next experiment, feeding and B51 excitability were analyzed $72 \mathrm{~h}$ after treatment. The TSWR and feeding were measured before, and $24 \mathrm{~h}$ and $72 \mathrm{~h}$ after treatment in trained and untrained animals. Both LTS (change in TSWR duration, trained: $1.94 \pm 0.23, n=34$; untrained: $1.33 \pm 0.13, n=29 ; P<0.05 ; U=347$ ) (Fig. 2A1) and suppression of feeding (difference in bites, trained: $-5.48 \pm 1.68$ bites, $n=42$; untrained: $1.81 \pm 1.31$ bites, $n=41 ; P<0.05 ; U=$ 492.5) (Fig. 2A2) were observed at $24 \mathrm{~h}$, confirming the effectiveness of training in this cohort of animals. However, $72 \mathrm{~h}$ after treatment, changes were not observed in either TSWR (change in TSWR duration, trained: $1.01 \pm 0.13, n=15$; untrained: $1.17 \pm$ $0.12, n=18 ; P=0.16 ; U=96$ ) (Fig. 2B1) or feeding (difference in bites, trained: $1.07 \pm 1.83$ bites, $n=41$; untrained: $2.18 \pm$ 1.33 bites, $n=40 ; P=0.93 ; U=809.5$ ) (Fig. 2B2), indicating that the behavioral changes were no longer present at the $72-\mathrm{h}$ time point.

Immediately after the 72-h post-tests, the buccal ganglia were removed, and B51 properties were measured. B51 burst threshold did not differ between trained $(17.00 \pm 1.74 \mathrm{nA}, n=22)$ and untrained animals $(15.69 \pm 2.32 \mathrm{nA}, n=13 ; P=0.73 ; U=132.5)$ (Fig. 2C1,C2). Additionally, no differences were observed between trained and untrained animals in B51 resting membrane potential (trained: $-53.59 \pm 2.51 \mathrm{mV}, n=25$; untrained: $-54.42 \pm 1.30 \mathrm{mV}$, $n=21 ; P=0.58 ; U=237$ ) or input resistance (trained: $2.21 \pm$ $0.17 \mathrm{M} \Omega, n=21$; untrained: $1.92 \pm 0.12 \mathrm{M} \Omega, n=16 ; P=0.42$; $U=141)$. The lack of training-specific changes in B51 excitability at the 72-h time point corroborates the view of B51 as a site of plasticity underlying the long-term suppression of feeding.

In the third experiment, we tested the hypothesis that 5-HT mediates the suppression of feeding produced by LTS training. Several lines of evidence suggested that 5-HT might contribute to such suppression. First, 5-HT is released into the hemolymph and into the neuropil following the delivery of sensitizing stimuli (e.g., Levenson et al. 1999; Marinesco and Carew 2002) and mediates changes in the withdrawal reflexes circuits underlying sensitization (e.g., Brunelli et al. 1976; Glanzman et al. 1989; 
A1

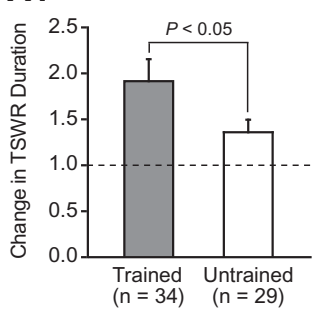

B1
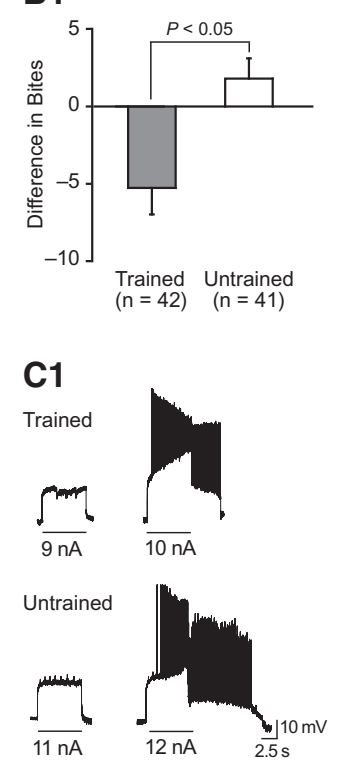

A2

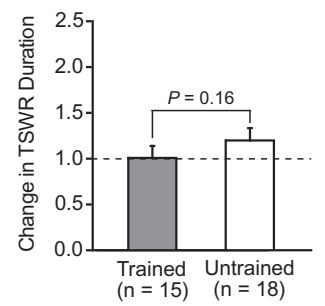

B2

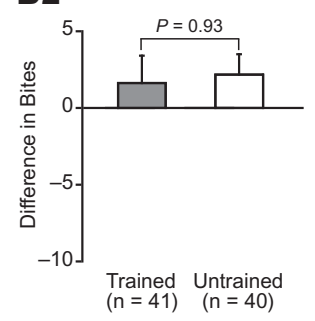

C2

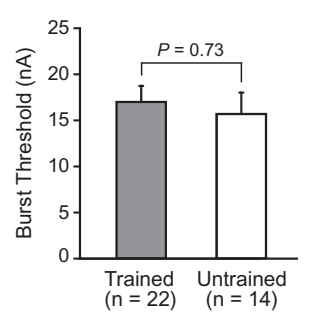

Figure 2. LTS, feeding suppression, and B51 decreased excitability were no longer observed $72 \mathrm{~h}$ after training. Training produced LTS, which lasted at least $24 \mathrm{~h}(A 1)$ but was not observed $72 \mathrm{~h}$ after treatment (A2). In the same group of animals, feeding was suppressed $24 \mathrm{~h}$ (B1) but not $72 \mathrm{~h}$ after treatment (B2). (C) LTS training did not alter B51 burst threshold $72 \mathrm{~h}$ after training. (C1) Sample traces of B51 burst threshold from trained and untrained animals. (C2) Summary data illustrate that B51 burst threshold did not differ significantly between trained and untrained animals $72 \mathrm{~h}$ after treatment.

Marinesco and Carew 2002). Second, 5-HT modulates feeding and its neural circuit (e.g., Rosen et al. 1989; Levenson et al. 1999; Kabotyanski et al. 2000). For example, application of 5-HT to the isolated buccal ganglion reduces the activity of an identified element in the feeding circuit, including pattern-initiation neuron B31/32 (Kabotyanski et al. 2000). Therefore, we investigated whether an in vivo treatment with $5-\mathrm{HT}$, which induces LTS (Levenson et al. 2000; Lyons et al. 2006; see Supplemental Material for details), modulates feeding and B51 excitability in a manner analogous to LTS training.

TSWR and feeding were measured before and $24 \mathrm{~h}$ after exposure to either 5-HT or seawater (control). 5-HT treatment induced LTS (change in TSWR duration, 5-HT: $1.87 \pm 0.33, n=14$; seawater: $0.93 \pm 0.173, n=8 ; P<0.05 ; U=24.5$ ) (Fig. 3A1) but did not suppress feeding (difference in bites, 5 -HT: $0.52 \pm 1.73$ bites, $n=19$; seawater: $0.42 \pm 1.95$ bites, $n=21 ; P=1.00 ; U=199$ ) (Fig. 3A2). Immediately after the 24 -h post-tests, the buccal ganglia were removed, and B51 properties were measured. No significant difference in burst threshold was measured between 5-HT-treated $(19.20 \pm 2.85 \mathrm{nA}, n=6)$ and seawater-treated animals (18.20 $\pm 3.38 \mathrm{nA}, n=11 ; P=0.90 ; U=23.5)$ (Fig. 3B1,B2).

We noticed that the average burst threshold of the seawatertreated group was unusually high, especially if compared to the control group in the first experiment (Fig. 1B2). However, these two studies were conducted independently with different populations of animals, which were used in parallel for treatment and control procedures (see Supplemental Material). Additionally, control measurements of B51 threshold fall within a broad range of values (from 7 to $14 \mathrm{nA}$ ) (Brembs et al. 2002; Lorenzetti et al. 2006). This variability prevents comparison of data across experiments (e.g., controls in Figs. 1B2 and 3B2) and requires treatment vs. control comparisons to isolate/exclude treatment-dependent effects (Brembs et al. 2002; Lorenzetti et al. 2006; Mozzachiodi et al. 2008).

5-HT treatment also did not affect resting membrane potential (5-HT: $-61.38 \pm 1.48 \mathrm{mV}, n=8$; seawater: $-57.92 \pm 1.42 \mathrm{mV}$, $n=12 ; P=0.12 ; U=27.5)$ or input resistance (5-HT: $2.06 \pm$ $0.07 \mathrm{M} \Omega, n=6$; seawater: $2.24 \pm 0.34 \mathrm{M} \Omega, n=11 ; P=0.48 ; U=$ 25.5). Finally, neither the peak amplitude (5-HT: $-6.87 \pm$ $1.66 \mathrm{mV}, n=6$; seawater: $-7.45 \pm 1.31 \mathrm{mV}, n=8 ; P=0.76$; $U=$ $21)$ nor the area (5-HT: $11.85 \pm 3.75$ arbitrary units, $n=6$; untrained: $10.50 \pm 2.74$ arbitrary units, $n=8 ; P=0.76 ; U=21)$ of the n.2,3-evoked cPSP differed between trained and untrained animals. These findings indicate that 5-HT treatment failed to produce the changes in feeding and B51 excitability that were observed after LTS training (Fig. 1A2,B2).

With this study, we have begun the analysis of the consequences of aversive experience on a nondefensive neural circuit in Aplysia. Our findings provide the first evidence of cellular plasticity produced by sensitizing stimuli outside the withdrawal-reflex neural circuits. In particular, LTS training induced a decrease in B51 intrinsic excitability (Fig. 1B). Because B51 plateau potentials appear to be necessary for the expression of ingestive BMPs (Nargeot et al. 1999a,b; Nargeot and Simmers 2011), a

\section{A1}

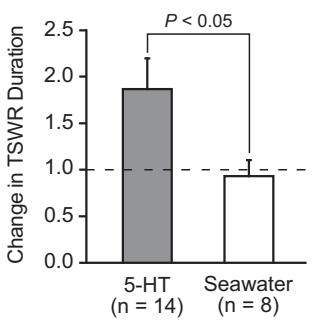

B1

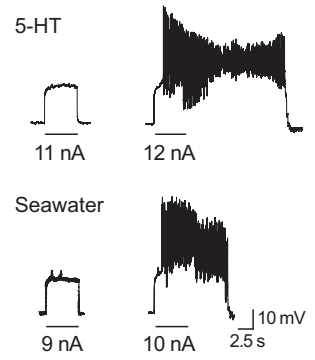

A2

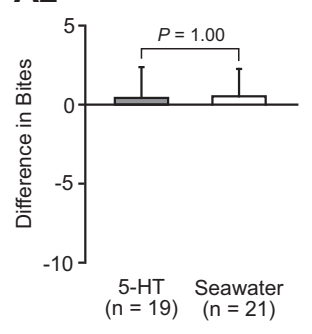

B2

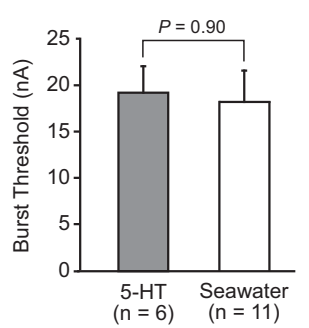

Figure 3. $5-\mathrm{HT}$ treatment failed to induce the suppression of feeding and the decrease in B51 excitability $24 \mathrm{~h}$ after treatment. 5-HT treatment induced LTS $(A 1)$ but did not alter feeding $(A 2)$. (B) 5-HT treatment did not alter B51 burst threshold $24 \mathrm{~h}$ after treatment. (B1) Sample traces of B51 burst threshold from 5-HT- and seawater-treated animals. (B2) Summary data illustrate that B51 burst threshold did not differ significantly between 5-HT-treated and seawater-treated animals $24 \mathrm{~h}$ after treatment. 
decrease in B51 excitability would modify their occurrence in a manner consistent with the reduced bites observed in vivo. The absence of changes in B51 resting membrane potential and input resistance indicates that LTS training likely modulates voltagedependent channels. Previous work revealed that B51 plateau potential does not depend on external $\mathrm{Ca}^{2+}$ (Plummer and Kirk 1990), suggesting that voltage-dependent $\mathrm{Na}^{+}$and $\mathrm{K}^{+}$currents are involved in its genesis and maintenance. Therefore, modulation of voltage-dependent $\mathrm{Na}^{+}$and/or $\mathrm{K}^{+}$channels may contribute to the reductions of B51 excitability produced by LTS training.

Combined with previous work that examined the effects of appetitive associative learning on B51 (Baxter and Byrne 2006; Mozzachiodi and Byrne 2010; Nargeot and Simmers 2011), our results provide further evidence of the decision-making nature of this neuron within the feeding neural circuit. Contrary to LTS training, operant reward learning enhances feeding in testing conditions identical to those used in this study (i.e., seaweed extract application) and increases B51 excitability (Brembs et al. 2002). Altogether, these findings suggest that opposite requirements to modulate feeding (enhancement/suppression), imposed by distinct learning tasks (operant reward/LTS training), might be achieved, at least in part, through modulation of the excitability (increase/reduction) of a common decision-making neuron. Although B51 plays a key role in influencing whether or not a bite is generated, it is unlikely the sole locus of plasticity produced by LTS training in the feeding neural circuit. Changes in neurons in both the cerebral and buccal ganglia may also contribute to the suppression of feeding. Putative additional sites of plasticity may include pattern-initiating neurons in the buccal ganglion, such as $\mathrm{B} 31 / 32$ and $\mathrm{B} 63$, as well as cerebral command-like interneurons (CBIs), which have the ability to drive the feeding neural circuit (e.g., Cropper et al. 2004).

In the last part of the study, we began to characterize the biochemical pathway responsible for the training-induced suppression of feeding. Our results indicate that 5-HT bath application, which induces LTS (Fig. 3A1), did not alter feeding or B51 excitability (Fig. 3A2,B1,B2). A simple interpretation of this experimental outcome is that 5-HT does not mediate the suppression of feeding produced by LTS training, thus suggesting that an additional modulator(s), triggered by sensitizing stimuli, modifies the activity of the feeding neural circuit. In this case, modulators, such as the small cardioactive peptide (SCP) and nitric oxide (NO), might be putative candidates to mediate the effects of LTS training because they modulate the feeding neural circuit in Aplysia (Wu et al. 2010; Susswein and Chiel 2012). However, it must be noted that the modulatory role of 5-HT in the feeding circuit is rather complex and not fully understood. Indeed, 5-HT appears to be capable of both increasing and decreasing the activity of the feeding neural circuit (e.g., Rosen et al. 1989; Kabotyanski et al. 2000). Therefore, we cannot rule out the possibility that the global increase in the systemic 5-HT levels, induced by 5-HT treatment, produced opposite compartmentalized effects on the feeding neural circuit, which cancelled each other and were not detected at the behavioral level. The development of an in vitro analog, expressing cellular correlates of both sensitization and suppression of feeding, would contribute importantly to further characterize the role of 5-HT and other modulators in the suppression of feeding, as it would allow manipulations that are not feasible in vivo, such as global or local inhibition/activations of individual biochemical pathways.

In conclusion, the present findings lay the foundation for the cellular and molecular characterization of the suppression of feeding produced by sensitization training. This analysis will provide an excellent opportunity to compare and contrast the mechanisms of plasticity induced in defensive and nondefensive neural circuits by aversive stimuli and ultimately lead to a better under- standing of the broad impact of aversive experience on the animal's behavioral repertoire.

\section{Acknowledgments}

This work was supported by start-up funds from the College of Science and Engineering (R.M.), by NIH-EARDA grant 5G11HD046353-05 (R.M.), and by the Texas Research Development Funds (R.M., M.L.W.). M.E.S.-J. was supported in part by NIH-EARDA grant 5G11HD046353-05. C.T. was supported by NSF-DBI grant 0602783. We thank Gustavo Peņa and Zachary Jones for many hours of animal training.

\section{References}

Acheampong A, Kelly K, Shields-Johnson M, Hajovsky J, Wainwright M, Mozzachiodi R. 2012. Rapid and persistent suppression of feeding behavior induced by sensitization training in Aplysia. Learn Mem 19: $159-163$.

Baxter DA, Byrne JH. 2006. Feeding behavior of Aplysia: A model system for comparing cellular mechanisms of classical and operant conditioning. Learn Mem 13: 669-680.

Brembs B, Lorenzetti FD, Reyes FD, Baxter DA, Byrne JH. 2002. Operant reward learning in Aplysia: Neuronal correlates and mechanisms. Science 296: 1706-1709.

Brunelli M, Castellucci V, Kandel ER. 1976. Synaptic facilitation and behavioral sensitization in Aplysia: Possible role of serotonin and cyclic AMP. Science 194: 1178-1181.

Carew TJ, Sahley CL. 1986. Invertebrate learning and memory: From behavior to molecules. Annu Rev Neurosci 9: 435-487.

Cleary LJ, Lee WL, Byrne JH. 1998. Cellular correlates of long-term sensitization in Aplysia. J Neurosci 18: 5988-5998.

Cropper EC, Evans CG, Hurwitz I, Jing J, Proekt A, Romero A, Rosen SC. 2004. Feeding neural networks in the mollusc Aplysia. Neurosignals 13: $70-86$.

Fioravante D, Antzoulatos EG, Byrne JH. 2008. Sensitization and habituation: Invertebrate. In Learning and memory: A comprehensive reference (ed. JH Byrne), pp. 31-51. Academic Press, Oxford, UK.

Glanzman DL, Mackey SL, Hawkins RD, Dyke AM, Lloyd PE, Kandel ER. 1989. Depletion of serotonin in the nervous system of Aplysia reduces the behavioral enhancement of gill withdrawal as well as the heterosynaptic facilitation produced by tail shock. J Neurosci 9: 4200-4213.

Kabotyanski EA, Baxter DA, Cushman SJ, Byrne JH. 2000. Modulation of fictive feeding by dopamine and serotonin in Aplysia. J Neurophysiol 83: $374-392$.

Kandel ER. 2001. The molecular biology of memory storage: A dialog between genes and synapses. Science 294: 1030-1038.

Kavaliers M, Choleris E. 2001. Antipredator responses and defensive behavior: Ecological and ethological approaches for the neurosciences. Neurosci Biobehav Rev 25: 577-586.

Khabour O, Levenson J, Lyons LC, Kategaya LS, Chin J, Byrne JH, Eskin A. 2004. Coregulation of glutamate uptake and long-term sensitization in Aplysia. J Neurosci 24: 8829-8837.

Kupfermann I. 1974. Feeding behavior in Aplysia: A simple system for the study of motivation. Behav Biol 10: 1-26.

LeDoux J. 2012. Rethinking the emotional brain. Neuron 73: 653-676.

Levenson J, Byrne JH, Eskin A. 1999. Levels of serotonin in the hemolymph of Aplysia are modulated by light/dark cycles and sensitization training. J Neurosci 19: 8094-8103.

Levenson J, Endo S, Kategaya LS, Fernandez RI, Brabham DG, Chin J, Byrne JH, Eskin A. 2000. Long-term regulation of neuronal high-affinity glutamate and glutamine uptake in Aplysia. Proc Natl Acad Sci 97: 12858-12863.

Lorenzetti FD, Mozzachiodi R, Baxter DA, Byrne JH. 2006. Classical and operant conditioning differentially modify the intrinsic properties of an identified neuron. Nat Neurosci 9: 17-19.

Lyons LC, Collado MS, Khabour O, Green CL, Eskin A. 2006. The circadian clock modulates core steps in long-term memory formation in Aplysia. J Neurosci 26: 8662-8671.

Marinesco S, Carew TJ. 2002. Serotonin release evoked by tail nerve stimulation in the CNS of Aplysia: Characterization and relationship to heterosynaptic plasticity. J Neurosci 22: 2299-2312.

Mozzachiodi R, Byrne JH. 2010. More than synaptic plasticity: Role of nonsynaptic plasticity in learning and memory. Trends Neurosci 33: $17-26$.

Mozzachiodi R, Lorenzetti FD, Baxter DA, Byrne JH. 2008. Changes in neuronal excitability serve as a mechanism of long-term memory for operant conditioning. Nat Neurosci 11: 1146-1148. 
Nargeot R, Simmers J. 2011. Neural mechanisms of operant conditioning and learning-induced behavioral plasticity in Aplysia. Cell Mol Life Sci 68: $803-816$.

Nargeot R, Baxter DA, Byrne JH. 1999a. In vitro analog of operant conditioning in Aplysia. I. Contingent reinforcement modifies the functional dynamics of an identified neuron. J Neurosci 19: 2247-2260.

Nargeot R, Baxter DA, Byrne JH. 1999b. In vitro analog of operant conditioning in Aplysia. II. Modifications of the functional dynamics of an identified neuron contribute to motor pattern selection. J Neurosci 19: $2261-2272$

Papes F, Logan DW, Stowers L. 2010. The vomeronasal organ mediates interspecies defensive behaviors through detection of protein pheromone homologs. Cell 141: 692-703.

Plummer MR, Kirk MD. 1990. Premotor neurons B51 and B52 in the buccal ganglia of Aplysia californica: Synaptic connections, effects on ongoing motor rhythms, and peptide modulation. J Neurophysiol 63: 539-558.

Rosen SC, Weiss KR, Goldstein RS, Kupfermann I. 1989. The role of a modulatory neuron in feeding and satiation in Aplysia: Effects of lesioning of the serotonergic metacerebral cells. J Neurosci 9: $1562-1578$.

Stopfer S, Carew TJ. 1988. Development of sensitization in the escape locomotion system in Aplysia. J Neurosci 8: 223-230.

Susswein AJ, Chiel HJ. 2012. Nitric oxide as a regulator of behavior: New ideas from Aplysia feeding. Prog Neurobiol 97: 304-317.

Susswein AJ, Kupfermann I, Weiss KR. 1976. The stimulus control of biting in Aplysia. J Comp Physiol [A] 108: 75-96.

Watkins AJ, Goldstein DA, Lee LC, Pepino CJ, Tillett SL, Ross FE, Wilder EM, Zachary VA, Wright WG. 2010. Lobster attack induces sensitization in the sea hare, Aplysia californica J Neurosci 30: 11028-11021.

Wu JS, Vilim FS, Hatcher NG, Due MR, Sweedler JV, Weiss KR, Jing J. 2010. Composite modulatory feedforward loop contributes to the establishment of a network state. J Neurophysiol 103: $2174-2184$.

Received August 7, 2013; accepted in revised form September 18, 2013. 


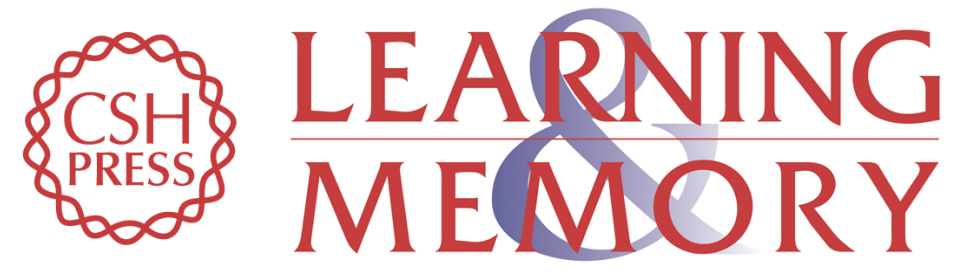

\section{Effects of aversive stimuli beyond defensive neural circuits: Reduced excitability in an identified neuron critical for feeding in Aplysia}

Maria E. Shields-Johnson, John S. Hernandez, Cody Torno, et al.

Learn. Mem. 2013, 20:

Access the most recent version at doi:10.1101/Im.028084.112

Supplemental Material

References

License

Email Alerting Service
http://learnmem.cshlp.org/content/suppl/2012/12/13/20.1.1.DC1

This article cites 32 articles, 16 of which can be accessed free at: http://learnmem.cshlp.org/content/20/1/1.full.html\#ref-list-1

Receive free email alerts when new articles cite this article - sign up in the box at the top right corner of the article or click here. 